\title{
Participation and Motivation in Obesity Treatment - A Qualitative Study of Teenagers' and Parents' Perceptions
}

\author{
Carina Sparud-Lundin ${ }^{1 *}$ and Karin Andersson ${ }^{2}$ \\ ${ }^{1}$ Institute of Health and Care Sciences, Sahlgrenska Academy at University of Gothenburg, Göteborg, Sweden \\ ${ }^{2}$ Child and Adolescent Specialist Center, Angered Hospital, Sweden
}

Received: February 19, 2015; Accepted: April 22, 2015; Published: May 06, 2015

*Corresponding author: Carina Sparud-Lundin, Institute of Health and Care Sciences, Sahlgrenska Academy at University of Gothenburg, Göteborg, Sweden, Tel: +46-31-7866389; Fax: +46-31-7866110; E-mail: carina.s-lundin@fhs.gu.se

\begin{abstract}
Aim: The aim was to describe teenagers' and parents' perceptions of participation in treatment and their view of motivation within the context of obesity treatment.
\end{abstract}

Methods: Qualitative interviews were conducted with 10 families (10 teenagers, aged 13 to 18 years and 6 parents) taking part in a family-based treatment model for childhood obesity. Data from interviews were processed with a phenomenographic analytic method.

Results: The categories motivation promotion, motivation demotion, conditions for participation and supportive treatment interventions outline participants' views on motivation and participation in the treatment of overweight/obesity. Motivation and opportunity for involvement in treatment is of great importance for parents and teenagers. Motivation was described as an important and necessary driving force for changing lifestyle behaviour.

Conclusions: Future treatment interventions need to focus on further strengthening families' participation and supporting motivation based on the experiences and suggestions that emerged in this study. For the health care sector, it is a challenge to develop comprehensive models that take families' conditions into account and to involve them in the design of childhood obesity treatment.

Keywords: Childhood Overweight/Obesity; Motivation; Participation; Motivational Interviewing; Health; Phenomenography; Interviews

\section{Introduction}

Overweight and obesity in children have increased worldwide in the last two decades and is now a widespread public health problem. In most European countries, overweight/obesity has increased between 10 and $50 \%$ over the past ten to twenty years [1]. In Sweden, 18 to $25 \%$ of children are overweight (isoBMI $>25$ ) and 3 to $4 \%$ of children are obese (isoBMI > 30) [2-5]. Because BMI does not work for children and adolescents, the International Obesity Task Force, has produced an extension of BMI that also works for children. isoBMI and the value is calculated in the same way as BMI for adults but the limits for classification of overweight and obesity vary for all ages from 2 to 18 years.

Obesity implies a large impact on people's health and self-esteem, and increases the risk for a number of serious diseases $[3,6]$. Social determinants further affect children's' ability to succeed with weight loss. Low education in parents, unemployment and social exclusion are factors that negatively affect health [3,6-8].

Family therapy has been shown to have some effect on overweight among children and adolescents [5,9-12]. These studies have demonstrated behaviour change and some weight loss after a few sessions. Nevertheless, merely advice to families within a primary care context seems to be too small effort to produce lasting results [13]. Some studies have showed better outcome when only parents received group support in combination with dietary information [14-16]. Other highlights the importance of active involvement of parents and children to succeed with overweight/obesity treatment $[17,18]$. Especially adolescents need individual support in the behaviour change process and together with parents in parallel. It is important, however, that the responsibility for change is not only put on the children/adolescents [17]. Previous studies about teenagers' experiences of being overweight have reported that they feel lonely, are in need of support from their parents and are searching for a context in their daily lives [19].

To achieve active involvement in obesity treatment, motivation in children and their parents can be assumed to play an important role. Motivational Interviewing (MI) has been used in various health promotion programmes to support participation and motivation when lifestyle changes have been required. The method can be a useful tool for improving the outcome of various programs for overweight and obese children [20,21]. However, behavioural therapy in relation to obesity treatment seems to provide better result at younger ages compared to teenagers [22]. A combination of MI and interventions with focus on family and the social situation was described to be a promising treatment in children with obesity and diabetes [23]. With obesity treatment, it is important to identify the teenagers' and the families' context 
for change. MI is based on the assumption that it is important to identify what degree of motivation individuals have and how ready they are for change [24]. The method focuses on the application of a change-oriented and person-centred conversation by means of open questions, reflections and summaries of the person's own thoughts, knowledge and motivation, which caregivers then try to build on, without judging $[24,25]$.

In summary, obesity treatment has proven to be a complex treatment and it can be difficult to achieve lasting results. In-depth knowledge of how parents and children look on participation and motivation when undergoing overweight/obesity treatment may contribute to the development of more appropriate methods. Therefore this study aims to describe teenagers' and parents' perceptions of participation in treatment and their view of motivation within the context of obesity treatment.

\section{Methods}

A qualitative approach based on phenomenography to capture the range of variation in human perceptions was used [26,27] to examine how parents and teenagers perceive participation and motivation in obesity treatment.

The study was conducted at a child and adolescent specialist centre in a Swedish suburb where a high percentage of the population is of foreign origin. The centre works on a family-based treatment model for child obesity. An important assumption is that motivation is of utmost significance to implement weight change and active involvement is a key factor for achieving lasting weight loss. Prior to the first meeting with the family, the team discusses the initial test results and growth curves. A few weeks later, the team meet the family for an initial assessment. In this meeting, the family's motivation and attitude towards the teenager's overweight are discussed. The parents and teenagers jointly meet the team during most visits, and sometimes individually. The physician focuses on medical issues and risk factors. The dietician works with nutrition and motivation, often with the whole family. The psychologist and counsellor work with psychological and social support services primarily for parents but also for the teenagers. Sometimes social services are involved for further support for parents in their parental role in the home. The physiotherapist works with motor assessments and assists in finding adequate physical activity for the teenager. The families meet the team on two or three occasions before motivational support according to the method of MI [24] is introduced by the nurse, to help the teenagers and their parents to find the strength required to implement weight loss. Prior to the interviews, parents and teenagers are asked to complete motivation scales. The scales encourage the participants to reflect on their own role in working with lifestyle changes. The treatment lasts between one to two years with meetings about once a month during the first year. Focus was not to evaluate the obesity treatment itself but rather to explore accounts of motivation and participation while experiencing professional support.

\section{Sample and data collection}

Teenagers with isoBMI $>30$, who had participated in obesity treatment at the centre during 2011-2012, were recruited using a consecutive sampling procedure. The coordinating paediatric nurse asked adolescents aged 13 to 18 years and their parents about their willingness to participate. They should have completed at least one motivation scale before the interview as it was considered to increase the possibilities of capturing the participants' reflections of motivation. The informants were interviewed during their first year of treatment.

In total 19 teenagers fulfilled the inclusion criteria and 19 families were invited. Nine families declined to participate due to lack of time or not wanting to participate. The total number of participants was 16 (10 teenagers- 7 girls and 3 boys, 4 mothers, 2 fathers). In all families except one, one or both parents were of foreign origin. Ethnic origin was South America, The Middle East, Poland and Finland. Interpreters were offered to not exclude participants with poor language comprehension but the offer was declined. Five teenagers chose to be interviewed with their parents (one with both parents) and three wanted to be interviewed on their own. Two teenagers were interviewed together.

The interviews started with the following questions: What is motivation to you? What is important for you to feel involved in the treatment? Follow-up questions were posed and the participants were encouraged to reflect on their views to obtain rich data. All interviews were audio-recorded and transcribed. Characteristics of the participants are presented in Table 1.

\section{Data analysis}

Phenomenographic analytic approach entails collecting various statements describing perceptions of the investigated phenomenon and delineates group of statements that have similar meanings [27]. The analysis was first carried out by reading all data several times to find the essence of the statements; identifying descriptions about participation in treatment and informants' views of motivation; preliminary description categories were created from a review of the preliminary subgroups and by classifying similar statements; description categories were defined by determining boundaries between the different categories and finally, categories were compared to identify similarities and dissimilarities as well as each category's unique characteristic. In the second phase of the analysis process,

Table 1: Demographic data on participating parents and their adolescents.

\begin{tabular}{|c|c|c|c|}
\hline Demographic & $\begin{array}{c}\text { Teenagers* } \\
(n=10)\end{array}$ & $\begin{array}{c}\text { Mothers } \\
(n=4)\end{array}$ & $\begin{array}{c}\text { Fathers } \\
(n=2)\end{array}$ \\
\hline \multicolumn{4}{|l|}{ Educational level } \\
\hline Secondary school & & 3 & 2 \\
\hline University level & & 1 & \\
\hline \multicolumn{4}{|l|}{ Family situation } \\
\hline Parents living together & 9 & 3 & 1 \\
\hline Single parent living alone & 1 & 1 & \\
\hline $\begin{array}{l}\text { Single parent living with new } \\
\text { partner }\end{array}$ & & & 1 \\
\hline Siblings in the family & 10 & & \\
\hline
\end{tabular}

* Age: 13 to 18 years 
Table 2: Description categories, sub-categories, and number of participants and statements corroborating each sub-category.

\begin{tabular}{|l|l|l|}
$\begin{array}{l}\text { Description categories and } \\
\text { sub-categories }\end{array}$ & $\begin{array}{l}\text { Number of corrobo- } \\
\text { rating participants } \\
(\mathrm{n}=16)\end{array}$ & $\begin{array}{l}\text { Number of } \\
\text { corroborating } \\
\text { statements }\end{array}$ \\
\hline
\end{tabular}

Motivation promotion

\begin{tabular}{|l|c|c|}
\hline Motivation as a starting point & 13 & 27 \\
\hline Motivation as a driving force & 13 & 35 \\
\hline $\begin{array}{l}\text { The motivation scales gave } \\
\text { thought }\end{array}$ & 13 & 22 \\
\hline Fear of disease & 6 & 15 \\
\hline
\end{tabular}

\section{Motivation demotion}

\begin{tabular}{|l|l|l|}
\hline Scaremongering & 6 & 9 \\
\hline Unsympathetic environment & 3 & 6 \\
\hline
\end{tabular}

\section{Conditions for participation}

\begin{tabular}{|l|c|c|}
\hline Strengthened parental role & 6 & 29 \\
\hline $\begin{array}{l}\text { Being able to choose and } \\
\text { influence }\end{array}$ & 25 & 60 \\
\hline
\end{tabular}

\begin{tabular}{|l|c|c|}
\hline Supportive treatment interventions \\
\hline $\begin{array}{l}\text { Goal-oriented and indirect } \\
\text { support }\end{array}$ & 10 & 31 \\
\hline Support in the parental role & 7 & 25 \\
\hline
\end{tabular}

the emerging subcategories and categories were discussed and negotiated several times by the two authors who are paediatric nurses, working at the clinic but not involved in the care of the included participants. The number of conceptions varies in the different categories and illustrates variation in informants' accounts in accordance with the phenomenographic approach.

\section{Results}

Four description categories were identified in the analysis and sub-categories define the content of the description categories. Table 2 includes categories and an overview of the number of statements corroborating each sub-category and the number of interviewees from whom these statements originate. Extracts from teenagers are cited as (T), and parents as (P).

\section{Motivation Promotion}

Motivation as a starting point: The participants described motivation as a starting point to enable change of behaviour. They described that change is not possible without motivation - motivation is needed for wanting to change one's life situation. The teenagers described that even though they know they need to make a change, it may be difficult to implement what is best for them. They could understand that it would be best not to accompany their friends to the café but that it is hard to resist when everyone else wants to do it. The parents also emphasised motivation as necessary to help their children to change behaviour, an important part of the parental role. Furthermore, they stressed the need of support from health care professionals to maintain their motivation.
"Motivation means that you feel the urge and desire to do something" $(P)$

"Motivation for me is the same thing as a goal. So, if I'm going to do it, I do it. Because if you hesitate, it will never be done" (T)

Motivation as a driving force: Both parents and teenagers described motivation as the driving force for achieving a change in their lives. First, the idea arose to make a change; then, they began to think about how the change could be implemented. When they had gathered strength, the change process commenced with motivation as the driving force. They described both small and large changes in everyday life. When the changes paid off, they felt satisfied and their motivation increased and when they failed it resulted in disappointment that decreased their motivation.

"Motivation is the driving force to achieve a result, that you somehow can imagine what gains and what benefits you can get by doing what you should and what you have set up to do" (P)

"It makes you sad when you don't see any results. When you see results you always want to continue" (T)

The motivation scales gave thought: A feature of the treatment is to make use of motivation scales to assess how motivated the teenagers and the parents are. They saw this as an aid to examine their own motivation, which was considered to be essential for the outcome. It gave thought and provided an opportunity for reflection. One of the teenagers contemplated a reformulation of the first question.

"Well I guess it was pretty good, you had to think about what you really want. The only thing that was difficult was the first question - how important is it for you to stand still / lose weight? For me, I just put a seven. If the question was split, I would have put a ten when considering my health and a seven when considering looks, then I don't really care" (T)

Fear of disease: Several of the parents and the teenagers described that a motivating factor was the fear of becoming ill. They told of their relatives who had suffered from illnesses as well as media coverage of risks of overweight and obesity. They called attention to the role of health care services when it comes to conveying the "true picture" of what an unhealthy lifestyle can entail. The understanding of risk factors created motivation.

"Because there are some things that you have heard several times, 'you have to lose weight', like I for example, and then I haven't really listened. But when I got this real picture, that I'm headed in the wrong direction and that my health is at stake, then when I realised this, then I got really motivated. It's great if you're realistic" $(T)$

\section{Motivation demotion}

Scaremongering: The parents and the teenagers reported that they took note of media reports about overweight and obesity. It could be both motivating and demotivating. Most often media reports were perceived as frightening and created negative emotions such as lack of confidence in being able to change their lives and regarding the negative consequences resulting from chronic overweight. 
"We know that overweight, it's not easy to live with. We have seen many TV programmes about those who are overweight and sometimes we say that maybe he will live with it. We also saw that those on TV had eczema on their bodies. There's a lot of nagging and stuff. Therefore we work hard so that he doesn't become overweight as an adult" $(P)$

Unsympathetic environment: The participants also described situations that affect motivation negatively. Some parents reported offensive comments from others as demotivating. They tried to support their teenagers to make changes but that the understanding from others was minor. When others did not see their daily efforts to help their child achieve a better lifestyle, they perceived this as negative for their motivation.

"Others tell me to tell my daughter not to eat so much, check on her and control her. They do not know that I do that... I do that every day" $(P)$

\section{Conditions for participation}

Strengthened parental role: The parents and the teenagers emphasised that transparency and understanding of the various treatment components resulted in engagement. They argued that it was good that the treatment is directed at both children and parents. Sometimes a parent needs support in parenting to help one's children in the best way. Everyday life was often filled with discussions and badgering. Parents then need to discuss how to respond to their children in order to provide better conditions for weight loss support. The parents described the need of getting support during the treatment; they must support the children and they personally need encouragement and guidance from care providers. To have influence was central and the parents emphasised how important it was not to feel alone with the problem. To not feel rejected or passed around to different services was also reported as important - it was likely to reduce the degree of motivation. A father described how weekends and summers were difficult periods because activities and schools were on break

"Obviously you have to be involved as a parent. As a parent, you may need more support and tools in how to respond to your children" $(P)$

Being able to choose and influence: During the interviews, it was discussed whether the option of participating in treatment was of importance. Both the parents and the teenagers believed it was evident that one has motivation if one was to participate in treatment, and they argued that the choice had some significance. Participating in overweight/obesity treatment without motivation would make it more difficult to achieve results. One family did not think one should be able to decline treatment because obesity is harmful to health. Especially teenagers described influencing the treatment as important. They claimed it was important that their parents are involved in everyday life and are supportive. Some parents felt that the treatment should primarily be directed to them and others argued that it should focus on the teenager.
"Yes, surely it must be important to be able to say yes or no, if you say no or if it is forced it will be probably not be good results. You have to want it yourself" (T)

\section{Supportive treatment interventions}

Goal-oriented and indirect support: The teenagers wanted support from the health care providers. They noted that if you do not feel well, it might be beneficial to talk to a psychologist. They wanted to have the help of the dietician with nutrition advice tailored to their circumstances. The health professionals' could generally be clearer with goals and realistic towards the families regarding how long weight loss can take. It would increase the motivation and sense of ownership. Several of the teenagers wanted the health care providers to support them in achieving fast results. Some teenagers requested that the health care providers should target their parents and support them; they argued that parents are responsible for purchasing and cooking, which must change to allow for weight loss.

"We are pleased that the dietician has adapted the diet according to our tastes and our weirdness" (T)

"Well, I believe so, because you ask about what we think and what can be improved. They ask all the time every time you're here, so you answer. I guess it's the last thing that I said, that I think you should be more for the parents, that you should concentrate on them a little bit more too" (T)

Support in the parental role: The parents talked about their feelings, which often involved being confirmed in their role as a parent and felt acknowledged that someone supports the family regarding the adolescent's obesity. It was considered to be a part of the parental role to support their children, but the parents expressed needs of "coaching" advice and guidance. One parent reported that it was equally important that the team motivated her child as it was that she did this every day. This parent did not want to feel left with the full responsibility for the overweight. The age of the child was reported to be of great importance; if the child is 10 years old, the parent has greater mandate to influence than with a seventeen-year-old. A seventeen-year-old is expected to a greater extent liberates her- or him self from the parents and has to take more responsibility. It was important for parents to receive information in order to be able to support their child at home. Responsibility for the child was considered to always lie with the parent.

"Certainly there are great differences in parenting a child in fifth grade or ninth grade. I need to be more supportive; previously I was more limit setting" $(P)$

"It's very important, you can solve the problem, it's not just me, in my language we say one hand cannot clap" $(P)$

\section{Discussions}

This study considered teenagers' and parents' perceptions in order to increase understanding of the significance of motivation and participation in the context of obesity treatment. The study yields important knowledge because previous studies on the treatment of childhood obesity with MI have primarily dealt with 
health care professionals' perceptions [20-22]. Furthermore, most participating families in this study were of foreign origin, which have a bearing on the outcome. The majority were from more family-oriented communities in contrast to the Swedish/ North European more individual-oriented culture. Regber [6] emphasises the need to reach all families with new interventions such as single parents, parents with low education and parents of foreign origin. These social determinants greatly affect the individual's ability to succeed in treatment. Exploring motivational and participatory aspects in health care settings serving multi-ethnic populations have the potential to contribute with more appropriate strategies for promoting life style changes.

Parents and teenagers need to acknowledge obesity as a health problem to be able to address the problem [21], and motivation among both families and health care providers is needed in order to achieve good results. This was confirmed in our study, in which the informants described the motivation as a starting point to change behaviour, and hence motivation is needed for wanting to change their lives. Therapists need to find out which level of motivation the families have to assess when treatment should begin [24]. Teenagers and parents described the use of the motivation scales in treatment as valuable, providing an opportunity for reflection, which in turn may be a step towards greater degree of motivation. In anticipation of such a motivation development, it may be necessary to wait for the right time and let the families gather strength before starting treatment. Our findings confirm that it is important to ask about adolescents' and their parents' perceptions of obesity treatment to identify and to increase their own motivation for change.

In line with the key components of MI [24,25], several of the participants reported that they are seeking support from the health care provider in a partner-like relationship. Parents reported that they do not want to feel alone with the responsibility of decreasing the child's overweight. They emphasised that transparency and understanding of the different components of the treatment result in commitment and participation. They approved that the treatment was directed at both children and parents. However, some families believed that the treatment should primarily be targeted at parents while others believed that the treatment should be targeted at the teenagers. The teenagers described the need for their own visits while highlighting that the parents need to be involved. This is supported by Kalavainen et al. [17] who found that the older the children are, the more important it appears that also the youth receives individual support in the behavioural change process. The degree of responsibility and participation in the treatment depends largely on the teenagers' maturity, age and relationship to the parents. This poses a challenge for health care providers to be perceptive and to meet each family based on their conditions. The participants felt that they were given the opportunity to be involved which led to increased motivation.

Since it has proven difficult to achieve long lasting results with childhood obesity treatment $[5,22]$, it seems important to be perceptive and responsive in the selection of treatment strategy for this target group. Involving teenagers in a reference group when developing treatment program, has great potential for developing the health care. The informants suggested that a motivational approach results in a higher degree of participation and that both motivation and participation is required to lose weight. The will may be there but individual and social obstacles make it difficult. Parents emphasised the need of support in their parental role. Providing opportunities for parental groups might be one way to strengthen parents; particularly in communities with many immigrants where families may have lost their previous social supporting network. Other suggestions for future treatment interventions can be to also include friends as they play a central role in most teenagers' daily lives. E-mail or chat can be a complement to current treatment because teenagers sometimes need to get motivational support between visits. However, ethical and confidential issues need to be addressed before this kind of treatment can be initiated [28].

\section{Methodological Considerations}

Strength of this study is the objective of reflecting teenagers' views, since they are considered to be an intractable group. Allowing adolescents to be interviewed with their parents may have influenced the findings but was applied to make the interview situation to feel as comfortable as possible. Some parents may have chosen to abstain in consultation with their teenagers because of language difficulties, despite the offer of an interpreter. There is a risk that they may have misunderstood questions because of not using an interpreter. The interviewer strived to be perceptive by asking supplementary questions when in doubt, to reflect the informants' perceptions in a fair manner. Limitations also include a relatively small sample, in particular the number of parents. Results are transferable to similar contexts and provide a picture of how teens and their parents perceive participation and motivation within the context of obesity treatment in clinical practice.

The description categories were compared to identify similarities and dissimilarities- variation in the participants' accounts. However, in line with most qualitative approaches, comparisons are not made between groups (e.g. girls-boys, mothers-fathers etc.). Following and describing the steps of the method thoroughly established rigour. To increase the dependability the second author reviewed that the analysis was grounded in data [29].

\section{Conclusion}

Motivation and participation are two key factors required to achieve results in obesity treatment. Parents and teenagers describe willingness to work with the weight, but also factors that promote or hinder motivation. Motivation is considered an important starting point but also a necessary driving force for achieving weight loss. Assessing families' levels of motivation seem to increase awareness of the significance of motivation and can constitute a basis for agreement and active participation in obesity treatment. It is essential in future research to evaluate the outcome of motivational support and increased participation in obesity treatment. 


\section{Acknowledgments}

The authors are grateful to the parents and teenagers who shared their perceptions of motivation and participation in relation to obesity treatment. Funding was provided by Angered Hospital.

\section{References}

1. Pearson D. Obesity. In: Ewles L (editor). Key topics in public health: essential briefings on prevention and health promotion. London: Elsevier Churchill Livingstone; 2005. p.79-102.

2. Boris : Child obesitas register in Sweden.

3. Britton M, Ränzlöv E. Förebyggande åtgärder mot fetma: en systematisk litteraturöversikt (Prevention of obesity- a systematic literature review). SBU, Statens beredning för medicinsk utvärdering, Stockholm, Sverige, 9185413011, 2005.

4. Lindberg T, Barnmedicin LH. Pediatric medicin, (2nd edn), Studentlitteratur, 2003, Lund, Sweden.

5. Nowicka P, Pietrobelli A, Flodmark CE. Low-intensity family therapy intervention is useful in a clinical setting to treat obese and extremely obese children. Int J Pediatr Obes. 2007; 2(4):211-7. doi: $10.1080 / 17477160701379810$.

6. Regber S. Barriers and facilitators of health promotion and obesity prevention in early childhood: a focus on parents results from the IDEFICS study. (Doctoral thesis). Gothenburg, Sweden: University of Gothenburg; 2014.

7. Organization WHO. Diet, nutrition and the prevention of chronic diseases. Report of a joint WHO/FAO expert consultation. Geneva, Switzerland: World Health Organization, 2003. Report No: 924120916X Contract No: 916.

8. Eidsdottir S, Kristjansson Å, Sigfusdottir I, Garber C, Allegrante J. Secular trends in owerweight and obesity among Icelandic adolescents: Do parental education levels and family structure play a part? Scand J Public Health. 2013; 41(4):384-91. doi: 10.1177/1403494813477927.

9. Flodmark CE. Management of the obese child using psychologicalbased treatments. Acta Paediatr Suppl. 2005; 94(448):14-22. doi: 10.1111/j.1651-2227.2005.tb02124.x.

10. Flodmark CE, Ohlsson T. Childhood obesity: from nutrition to behaviour. Proc Nutr Soc. 2008; 67(4):356-62. doi: 10.1017/ S0029665108008653.

11. Kitzmann KM, Beech BM. Family-based interventions for pediatric obesity: Methodological and conceptual challenges from family psychology. J Fam Psychol. 2006; 20(2):175-89. doi:o $\mathrm{rg} / 10.1037 / 0893-3200.20 .2 .175$.

12. Summerbell CD, Waters E, Edmunds LD, Kelly S, Brown T, Campbell KJ. Interventions for preventing obesity in children. Cochrane Database Syst Rev. 2005; (3):CD001871. doi: 10.1002/14651858.CD001871. pub2.

13. McCallum Z, Wake M, Gerner B, Baur LA, Gibbons K, Gold L, et al. Outcome data from the LEAP (Live, Eat and Play) trial: a randomized controlled trial of a primary care intervention for childhood overweight/mild obesity. Int J Obes (Lond). 2007; 31(4):630-6. doi:10.1038/sj.ijo.0803509.

14. Golley RK, Magarey AM, Baur LA, Steinbeck KS, Daniels LA. Twelve- month effectiveness of a parent-led, family-focused weightmanagement program for prepubertal children: a randomized, controlled trial. Pediatrics. 2007; 119(3):517-25. doi: 10.1542/ peds.2006-1746.

15. Golan M, Crow S. Targeting Parents Exclusively in the Treatment of Childhood Obesity: Long-Term Results. Obes Res. 2004; 12(2):357-61. doi: 10.1038/oby.2004.45.

16. Golan M, Weizman A, Apter A, Fainaru M. Parents as the exclusive agents of change in the treatment of childhood obesity. Am J Clin Nutr. 1998; 67(6):1130-5.

17. Kalavainen MP, Korppi MO, Nuutinen OM. Clinical efficacy of groupbased treatment for childhood obesity compared with routinely given individual counseling. Int J Obes (Lond). 2007; 31(10):1500-8.. doi:10.1038/sj.ijo.0803628.

18.Tyler DO, Horner SD. Family-centered collaborative negotiation: A model for facilitating behavior change in primary care. J Am Acad Nurse Pract. 2008; 20(4):194-203. doi: 10.1111/j.1745-7599.2007.00298.x.

19. Mériaux BG, Berg M, Hellström AL. Everyday experiences of life, body and well-being in children with overweight. Scand J Caring Sci. 2010; 24(1):14-23. doi: 10.1111/j.1471-6712.2008.00678.x

20. Müllersdorf M, Zuccato LM, Nimborg J, Eriksson H. Maintaining professional confidence-monitoring work with obese schoolchildren with support of an action plan. [Scand J Caring Sci. 2010; 24(1):131-8. doi: 10.1111/j.1471-6712.2009.00696.x.

21. Söderlund LL, Nordqvist C, Angbratt M, Nilsen P. Applying motivational interviewing to counselling overweight and obese children. Health Educ Res 2009; 24(3):442-9. doi: 10.1093/her/cyn039.

22. Danielsson P, Kowalski J, Ekblom Ö, Marcus C. Response of severely obese children and adolescents to behavioral treatment. Arch Pediatr Adolesc Med. 2012; 166(12):1103-8. doi: 10.1001/2013.

23. Christie D, Channon S. The potential for motivational interviewing to improve outcomes in the management of diabetes and obesity in paediatric and adult populations: a clinical review. Diabetes Obes Metab. 2014; 16(5):381-7. doi: 10.1111/dom.12195

24. Barth T, Näsholm C. Motiverande samtal-MI: att hjälpa en människa till förändring på hennes egna villkor (Motivational interviewing, MI helping people to change on her own terms). Lund, Sweden: Studentlitteratur; 2006.

25. Miller W, Rollnick S. Motiverande samtal-Hur man hjälper människor att bli villiga, kunniga och redo att genomföra förändringar som förbättrar kvaliteten i deras liv. (Motivational interviewing, how to help people to become willing, knoweledgeable, and ready to implement changes that improve the quality of their lives). Norrköping, Sweden: Kriminalvårdens förlag; 2003.

26. Marton F, Om lärande BS. Learning and awareness, Studentlitteratur, 2000, Lund, Sweden.

27.Sjöström B, Dahlgren LO. Applying phenomenography in nursing research. J Adv Nurs. 2002; 40(3):339-45. doi: 10.1046/j.13652648.2002.02375.x

28. Ekberg J. Online health promoting communities: Design, implementation and formative evaluation of an intervention. (Doctoral thesis). Linköping, Sweden: Linköping University; 2012.

29. Lincoln YS, Guba EG. Naturalist inquiry. Sage, 1985, USA. 